\title{
Q\&A: How do gene regulatory networks control environmental responses in plants?
}

Ying Sun ${ }^{1}$ and José R. Dinneny ${ }^{1,2^{*}}$

\begin{abstract}
A gene regulatory network (GRN) describes the hierarchical relationship between transcription factors, associated proteins, and their target genes. Studying GRNs allows us to understand how a plant's genotype and environment are integrated to regulate downstream physiological responses. Current efforts in plants have focused on defining the GRNs that regulate functions such as development and stress response and have been performed primarily in genetically tractable model plant species such as Arabidopsis thaliana. Future studies will likely focus on how GRNs function in non-model plants and change over evolutionary time to allow for adaptation to extreme environments. This broader understanding will inform efforts to engineer GRNs to create tailored crop traits.
\end{abstract}

\section{Question 1: What is a gene regulatory network?}

A gene regulatory network (GRN) is composed of molecular regulators such as transcription factors (TFs) that bind to short, non-coding DNA sequences called cis-regulatory elements (CREs), which are typically located in the promoter region of a gene $[1,2]$. Transcriptional regulators and their target genes form an interconnected regulatory network that integrates endogenous and environmental cues into changes in gene expression (Fig. 1) [3-5].

\section{Question 2: How will studying GRNs improve our understanding of plant biology?}

GRNs are often composed of thousands of connections between TFs and target genes that together, regulate many cellular functions. GRNs are complex and can be differentially regulated across tissue types and organs during plant develop or environmental acclimation [6-8].

\footnotetext{
* Correspondence: dinneny@stanford.edu
${ }^{1}$ Department of Biology, Stanford University, 371 Serra Mall, Stanford, CA

* Correspondence: dinneny@stanford.edu 94305, USA

${ }^{2}$ Department of Plant Biology, Carnegie Institution for Science, 260 Panama St, Stanford, CA 94305, USA
}

(c) Dinneny et al. 2018 Open Access This article is distributed under the terms of the Creative Commons Attribution 4.0 International License (http://creativecommons.org/licenses/by/4.0/), which permits unrestricted use, distribution, and reproduction in any medium, provided you give appropriate credit to the original author(s) and the source, provide a link to the Creative Commons license, and indicate if changes were made. The Creative Commons Public Domain Dedication waiver (http://creativecommons.org/publicdomain/zero/1.0/) applies to the data made available in this article, unless otherwise stated.
Such complexity can be difficult to tackle experimentally because each part of the GRN requires many experiments to characterize each part of the GRN. To understand the function of this network in the regulation of a process of interest, it can be useful to identify points within the network that are most critical. These points in the network are frequently interaction hubs that target, or are targets of, many other genes and proteins in the network. Functionally characterizing these points within GRNs will likely improve our understanding of the biology of the plant [9].

\section{Question 3: Why have most GRN studies in plants utilized Arabidopsis as a model?}

Many studies to understand the function of GRNs have used the model plant Arabidopsis thaliana because of the substantial genetic resources generated by the research community [10]. Arabidopsis is distributed across a wide range of habitats around the globe. Its genetic diversity has contributed to its ability to adapt to local environments. The genetic diversity within Arabidopsis provides an opportunity for understanding how the evolution of GRNs could contribute to environmental adaptations [11, 12]. To date, the genomes of over 1000 natural accessions of Arabidopsis from around the world have been sequenced and can be used to profile the functional effects of sequence variation on plant physiology [13]. Furthermore, relatives of Arabidopsis have been used to understand how environmental response traits may have evolved [14]. Currently, more than 285 plant genomes have been sequenced and span more than nine families of vascular plants, including 14 in the Brassicaceae family to which Arabidopsis belongs $[15,16]$. Characterizing gene content within plant genomes has revealed that plants have a large number of TF families, suggesting that they have extensive GRNs like other complex eukaryotes [17].

\section{Question 4: How do we currently study GRNs?}

Recent studies of GRNs have focused on defining the genes and proteins that make up the network and the molecular 


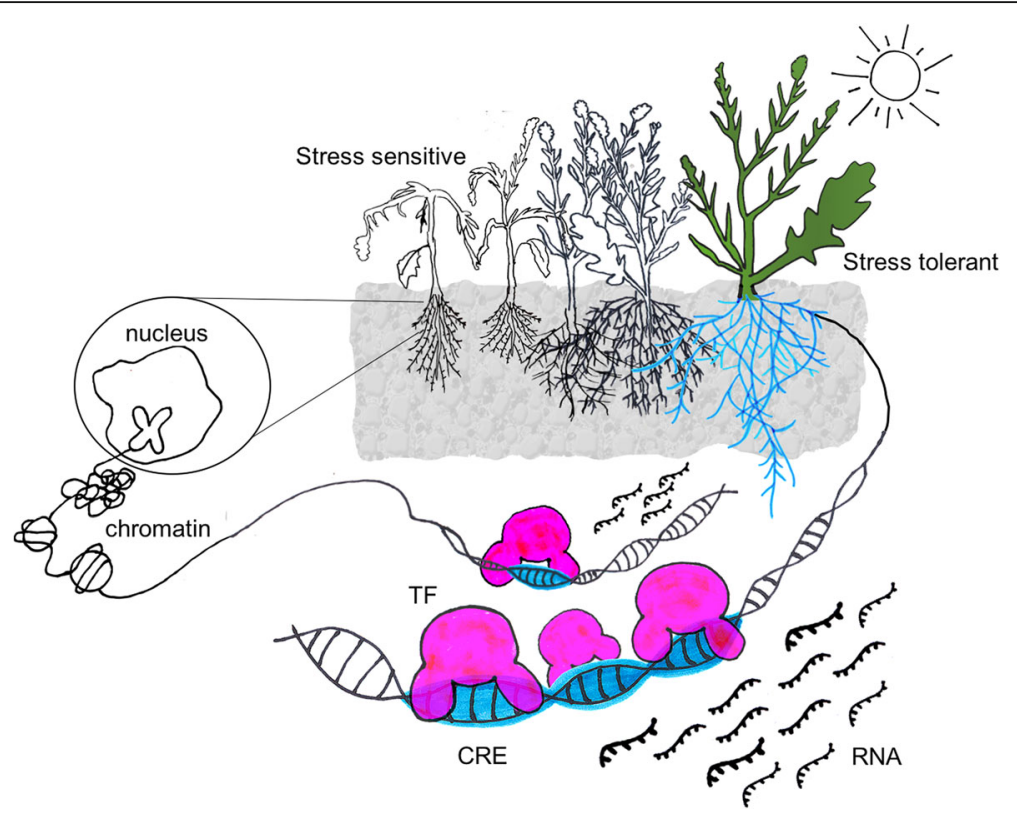

Fig. 1. Plants exposed to stress in the environment elicit changes in the expression of genes mediated by transcription factors (TF). Interactions between TF and their associated cis-regulatory element (CRE) regulate the abundance of RNA expressed from different genes. Combinations of TF-CRE interaction lead to the establishment of gene regulatory networks (GRNs). Variation in the GRN may lead to different responses of the plants to the environmental stress

interactions that regulate those genes and proteins. This has been facilitated by the establishment of genome-wide datasets including whole genome sequences and transcriptomic profiling in different tissues and conditions. More recently, high-throughput assays to profile TF binding site preference and chromatin structure has established how TF-DNA interaction influences the expression of genes within a GRN [18]. Construction of a GRN can also focus on TFs and target genes that likely function together in a specific biological pathway. For example, a GRN associated with secondary cell wall biosynthesis was constructed using yeast-1-hybrid assays and led to the discovery of stressresponsive changes in wall composition [19]. Additionally, the global-scale analysis of TF-target interactions using ChIP-Seq established an extensive GRN acting downstream of 21 TFs controlling response to the hormone abscisic acid (ABA) [20]. In vitro biochemical assays such as DNA affinity purification and sequencing (DAP-Seq) have also been used to broadly survey the direct genomic targets of several hundred TFs [21].

Additional computational tools are being developed so GRNs can be utilized to understand dynamic regulatory processes in plants. For example, the Environmental Gene Regulatory Influence Network (EGRIN) uses an algorithm to incorporate genome-scale transcriptome data from controlled and agricultural field experiments, and chromatin accessibility measurements into a model that predicts TF activity in response to changing environmental conditions [22]. Integrating multiple layers of regulation improves the predictive power of GRNs and can identify potential mechanisms for crosstalk between pathways [23]. Incorporating tissue and developmental stage-specific transcriptome data identified TF nodes that function in both stress and developmental signaling pathways [24]. These tools have been powerful in determining how groups of genes within GRNs are being regulated together and improves our knowledge of how genotype determines phenotype.

\section{Question 5: How does genetic variation affect the architecture of GRNs?}

Genetic variation within a species can have important effects on a GRN; changes in the coding sequence of a TF can change binding site preference, and sequence variation in promoters can result in the gain or loss of CREs [25]. To understand how sequence variation ultimately leads to differences in downstream physiology, GRNs can be constructed to include sequence differences that exist within a species or across species [26]. Analysis of genetic variation in Arabidopsis has revealed a greater number of polymorphisms in the promoter regions of drought and cold responsive genes than genes with other functions, suggesting that differences in CRE composition may be involved in local adaptation to environmental stress [27]. It is likely that comparing GRNs between species will help identify points in the network where genetic variation contributes to functional differences in gene regulatory mechanisms [26]. 


\section{Question 6: How can GRNs be experimentally manipulated?}

GRNs can be experimentally manipulated using gene knockouts, gene silencing, and editing approaches, such as viral-induced gene silencing (VIGS) and clustered regularly interspaced short palindromic repeats (CRISPR)/ CAS9 system, respectively. Functional characterization of genes in GRNs through mutational analysis can help to validate the relationships between TFs, their target genes, and the phenotypes GRNs govern. The development of the (CRISPR)/CAS9 system has also greatly improved the specificity, efficiency, and throughput of genome editing [28]. Recently, the CAS9 system was used to create different promoter isoforms and this led to novel inflorescence architectures that affected tomato yield [29]. Parts of GRNs can also be reconstituted in heterologous systems to identify the necessary components needed to compose a GRN [30]. This has been effectively demonstrated for the auxin signaling pathway, where engineered yeast are able to induce target genes in response to exogenously supplied hormone [31,32].

\section{Question 7: What are the future opportunities for understanding GRNs?}

Our ability to predict the function and dynamical states of GRNs will be enhanced by improvements in computational modeling. Using Bayesian networks, GRNs can be inferred with small false positive rates. Markov models allow stochastic GRN dynamics to be studied. Additionally, neural models with higher learning rate and better predictive power are being used to study all possible gene-to-gene regulatory interactions. The Extreme learning machine is able to reconstruct predictive GRNs from only transcriptomic datasets [33]. Future questions the field may address will include: What datasets are needed to build predictive GRNs? Based solely on the genome of a plant, can we predict the adaptive traits the plant has? How do GRNs change over evolutionary time and during domestication, and can we domesticate plants more efficiently through an understanding of the GRN?

\section{Question 9: Where can I find more information?}

- Gene regulatory networks [1-3, 26, 34, 35]

- The diversity of TF families in plants [17]

- Current updates on synthetic biology $[30,36,37]$

- Abiotic stress and $\mathrm{NaCl}$ stress in plants [38-43]

- Effects of the environment on root systems $[44,45]$

- ABA and signals involved in plant stress response [46]

- Plant plasticity and evolution of tolerance traits $[47,48]$

- Impact of CRE on stress response [49]

- Spatio-temporal GRNs [6, 22, 50-54]

- Halophytes and stress tolerant plants [55-60]

\section{Acknowledgements}

Funding was provided by the Carnegie Institution for Science Endowment and an HHMI-Simons Foundation Faculty Scholar award to JRD and a National Science Foundation Graduate Research Fellowship to YS.

\section{Authors' contributions}

YS and JD wrote and edited the paper. Both authors read and approved the final manuscript.

\section{Competing interests}

The authors declare that they have no competing interests.

\section{Publisher's Note}

Springer Nature remains neutral with regard to jurisdictional claims in published maps and institutional affiliations.

Published online: 11 April 2018

\section{References}

1. Geertz M, Maerkl SJ. Experimental strategies for studying transcription factor-DNA binding specificities. Brief Funct Genomics. 2010;9:362-73.

2. Li Y, Chen C-Y, Kaye AM, Wasserman WW. The identification of cisregulatory elements: a review from a machine learning perspective. Biosystems. 2015;138:6-17.

3. Macneil LT, Walhout AJM. Gene regulatory networks and the role of robustness and stochasticity in the control of gene expression. Genome Res. 2011;21:645-57.

4. Carroll SB. Evo-devo and an expanding evolutionary synthesis: a genetic theory of morphological evolution. Cell. 2008;134:25-36. http://www. sciencedirect.com/science/article/pii/S0092867408008179

5. Yamaguchi-Shinozaki K, Shinozaki K. Transcriptional regulatory networks in cellular responses and tolerance to dehydration and cold stresses. Annu Rev Plant Biol. 2006;57:781-803.

6. Brady SM, Orlando DA, Lee J-Y, Wang JY, Koch J, Dinneny JR, et al. A highresolution root spatiotemporal map reveals dominant expression patterns. Science. 2007;318:801-6.

7. Dinneny JR, Long TA, Wang JY, Jung JW, Mace D, Pointer S, et al. Cell identity mediates the response of Arabidopsis roots to abiotic stress. Science. 2008;320:942-5.

8. Kilian J, Whitehead D, Horak J, Wanke D, Weinl S, Batistic O, et al. The AtGenExpress global stress expression data set: protocols, evaluation and model data analysis of UV-B light, drought and cold stress responses. Plant J. 2007:50:347-63.

9. Rebeiz M, Patel NH, Hinman VF. Unraveling the Tangled Skein: The Evolution of Transcriptional Regulatory Networks in Development. Annu Rev Genomics Hum Genet. 2015;16:103-31.

10. Provart NJ, Alonso J, Assmann SM, Bergmann D, Brady SM, Brkljacic J, et al. 50 years of Arabidopsis research: highlights and future directions. New Phytol. 2016;209:921-44.

11. Fournier-Level A, Korte A, Cooper MD, Nordborg M, Schmitt J, Wilczek AM A map of local adaptation in Arabidopsis thaliana. Science. 2011;334:86-9.

12. Weigel D. Natural variation in Arabidopsis: from molecular genetics to ecological genomics. Plant Physiol. 2012; http://www.plantphysiol.org/ content/158/1/2.short

13. $1001 \mathrm{Genomes}$ Consortium. 1,135 genomes reveal the global pattern of polymorphism in Arabidopsis thaliana. Cell. 2016;166:481-91.

14. Chang C, Bowman JL, Meyerowitz EM. Field guide to plant model systems. Cell. 2016;167:325-39.

15. NCBI. Genome List. https://www.ncbi.nlm.nih.gov/genome/browse/ \#!/overview/brassicaceae. Accessed Dec 122017.

16. Cheng F, Liu S, Wu J, Fang L, Sun S, Liu B, et al. BRAD, the genetics and genomics database for Brassica plants. BMC Plant Biol. 2011;11:136.

17. Lehti-Shiu MD, Panchy N, Wang P, Uygun S, Shiu S-H. Diversity, expansion, and evolutionary novelty of plant DNA-binding transcription factor families. Biochim Biophys Acta. 1860;2017:3-20.

18. Lister R, Gregory BD, Ecker JR. Next is now: new technologies for sequencing of genomes, transcriptomes, and beyond. Curr Opin Plant Biol. 2009:12:107-18.

19. Taylor-Teeples M, Lin L, de Lucas M, Turco G, Toal TW, Gaudinier A, et al. An Arabidopsis gene regulatory network for secondary cell wall synthesis. Nature. 2015;517:571-5. 
20. Song L, Huang S-SC, Wise A, Castanon R, Nery JR, Chen H, et al. A transcription factor hierarchy defines an environmental stress response network. Science. 2016;354 Available from: https://doi.org/10.1126/ science.aag 1550

21. O'Malley RC, Huang S-SC, Song L, Lewsey MG, Bartlett A, Nery JR, et al. Cistrome and epicistrome features shape the regulatory DNA landscape. Cell. 2016;165:1280-92

22. Wilkins O, Hafemeister C, Plessis A, Holloway-Phillips M-M, Pham GM, Nicotra $A B$, et al. EGRINs (environmental gene regulatory influence networks) in rice that function in the response to water deficit, high temperature, and agricultural environments. Plant Cell. 2016;28:2365-84

23. Walley JW, Sartor RC, Shen Z, Schmitz RJ, Wu KJ, Urich MA, et al. Integration of omic networks in a developmental atlas of maize. Science. 2016:353:814-8.

24. Miao Z, Han Z, Zhang T, Chen S, Ma C. A systems approach to a spatiotemporal understanding of the drought stress response in maize. Sci Rep. 2017;7:6590

25. Johnson AD. The rewiring of transcription circuits in evolution. Curr Opin Genet Dev. 2017:47:121-7.

26. Thompson D, Regev A, Roy S. Comparative analysis of gene regulatory networks: from network reconstruction to evolution. Annu Rev Cell Dev Biol. 2015;31:399-428.

27. Lasky JR, Des Marais DL, Lowry DB, Povolotskaya I, McKay JK, Richards JH, et al. Natural variation in abiotic stress responsive gene expression and local adaptation to climate in Arabidopsis thaliana. Mol Biol Evol. 2014; 31:2283-96.

28. Zsögön A, Cermak T, Voytas D, Peres LEP. Genome editing as a tool to achieve the crop ideotype and de novo domestication of wild relatives: case study in tomato. Plant Sci. 2017;256:120-30.

29. Rodríguez-Leal D, Lemmon ZH, Man J, Bartlett ME, Lippman ZB. Engineering quantitative trait variation for crop improvement by genome editing. Cell. 2017;171:470-80. e8

30. Nemhauser $\lrcorner$, Torii KU. Plant synthetic biology for molecular engineering of signalling and development. Nat Plants. 2016;2:16010.

31. Pierre-Jerome E, Jang SS, Havens KA, Nemhauser JL, Klavins E. Recapitulation of the forward nuclear auxin response pathway in yeast. Proc Natl Acad Sci U S A. 2014:111:9407-12

32. Pierre-Jerome E, Moss BL, Lanctot A, Hageman A, Nemhauser JL. Functional analysis of molecular interactions in synthetic auxin response circuits. Proc Natl Acad Sci U S A. 2016;113:11354-9.

33. Rubiolo M, Milone $\mathrm{DH}$, Stegmayer $\mathrm{G}$. Extreme learning machines for reverse engineering of gene regulatory networks from expression time series. Bioinformatics. 2017; https://doi.org/10.1093/bioinformatics/btx730

34. Sinha NR, Rowland SD, Ichihashi Y. Using gene networks in EvoDevo analyses. Curr Opin Plant Biol. 2016;33:133-9.

35. Wittkopp PJ, Kalay G. Cis-regulatory elements: molecular mechanisms and evolutionary processes underlying divergence. Nat Rev Genet. 2011;13:59-69.

36. Braguy J, Zurbriggen MD. Synthetic strategies for plant signalling studies: molecular toolbox and orthogonal platforms. Plant J. 2016;87:118-38.

37. Samodelov SL, Zurbriggen MD. Quantitatively understanding plant signaling: novel theoretical-experimental approaches. Trends Plant Sci. 2017;22:685-704.

38. Pereira A. Plant abiotic stress challenges from the changing environment. Front Plant Sci. 2016;7:1123.

39. Munns R, Tester M. Mechanisms of salinity tolerance. Annu Rev Plant Biol. 2008;59:651-81.

40. Zhu J-K. Abiotic stress signaling and responses in plants. Cell. 2016; 167:313-24.

41. Dinneny JR. Traversing organizational scales in plant salt-stress responses. Curr Opin Plant Biol. 2015;23:70-5.

42. Feng $W$, Lindner $H$, Robbins NE 2nd, Dinneny JR. Growing out of stress: the role of cell- and organ-scale growth control in plant water-stress responses. Plant Cell. 2016;28:1769-82.

43. Hasegawa PM, Bressan RA, Zhu J-K, Bohnert HJ. Plant cellular and molecular responses to high salinity. Annu Rev Plant Physiol Plant Mol Biol. 2000; 51:463-99.

44. Rellán-Álvarez R, Lobet G, Dinneny JR. Environmental control of root system biology. Annu Rev Plant Biol. 2016;67:619-42.

45. Brophy JAN, LaRue T. Dinneny JR. Semin Cell Dev Biol: Understanding and engineering plant form; 2017. https://doi.org/10.1016/j.semcdb.2017.08.051

46. Zhu J-K. Salt and drought stress signal transduction in plants. Annu Rev Plant Biol. 2002;53:247-73.
47. Des Marais DL, Juenger TE. Pleiotropy, plasticity, and the evolution of plant abiotic stress tolerance. Ann N Y Acad Sci. 2010;1206:56-79.

48. Nicotra AB, Atkin OK, Bonser SP, Davidson AM, Finnegan EJ, Mathesius U, et al. Plant phenotypic plasticity in a changing climate. Trends Plant Sci. 2010;15:684-92.

49. Zou C, Sun K, Mackaluso JD, Seddon AE, Jin R, Thomashow MF, et al. Cis-regulatory code of stress-responsive transcription in Arabidopsis thaliana. Proc Natl Acad Sci U S A. 2011;108:14992-7.

50. Birnbaum K, Shasha DE, Wang JY, Jung JW, Lambert GM, Galbraith DW, et al. A gene expression map of the Arabidopsis root. Science. 2003; 302:1956-60.

51. Walker L, Boddington C, Jenkins D, Wang Y, Grønlund JT, Hulsmans J, et al. Changes in gene expression in space and time orchestrate environmentally mediated shaping of root architecture. Plant Cell. 2017;29:2393-412.

52. Sonawane AR, Platig J, Fagny M, Chen C-Y, Paulson JN, Lopes-Ramos CM, et al. Understanding tissue-specific gene regulation. Cell Rep. 2017; 21:1077-88.

53. Uygun S, Seddon AE, Azodi CB, Shiu S-H. Predictive models of spatial transcriptional response to high salinity. Plant Physiol. 2017;174:450-64.

54. Krishnan A, Gupta C, Ambavaram MMR, Pereira A. RECoN: Rice environment Coexpression network for systems level analysis of abiotic-stress response. Front Plant Sci. 2017:8:1640.

55. Wu H-J, Zhang Z, Wang J-Y, Oh D-H, Dassanayake M, Liu B, et al. Insights into salt tolerance from the genome of Thellungiella salsuginea. Proc Natl Acad Sci U S A. 2012;109:12219-24.

56. Orsini F, D'Urzo MP, Inan G, Serra S, Oh D-H, Mickelbart MV, et al. A comparative study of salt tolerance parameters in 11 wild relatives of Arabidopsis thaliana. J Exp Bot. 2010;61:3787-98.

57. Oh D-H, Hong H, Lee SY, Yun D-J, Bohnert HJ, Dassanayake M. Genome structures and transcriptomes signify niche adaptation for the multiple-iontolerant extremophyte Schrenkiella parvula. Plant Physiol. 2014;164:2123-38.

58. Dassanayake M, Oh D-H, Hong H, Bohnert HJ, Cheeseman JM. Transcription strength and halophytic lifestyle. Trends Plant Sci. 2011;16:1-3.

59. Oh D-H, Dassanayake M, Haas JS, Kropornika A, Wright C, d'Urzo MP, et al. Genome structures and halophyte-specific gene expression of the extremophile Thellungiella parvula in comparison with Thellungiella salsuginea (Thellungiella halophila) and Arabidopsis. Plant Physiol. 2010; 154:1040-52.

60. Oh D-H. Dassanayake M, Bohnert HJ. Cheeseman JM Life at the extreme: lessons from the genome Genome Biol. 2012;13:241. 